\title{
Analysis of the Long-Term Corrosion Behavior of X80 Pipeline Steel in Acidic Red Soil Using Electrical Resistance Test Technique
}

\author{
Shuaixing Wang, ${ }^{1,2}$ Daoxin Liu, ${ }^{1}$ Nan Du, ${ }^{2}$ Qing Zhao, ${ }^{2}$ and Jinhua Xiao ${ }^{2}$ \\ ${ }^{1}$ Institute of Corrosion and Protection, Northwestern Polytechnical University, Xian 710072, China \\ ${ }^{2}$ School of Material Science and Engineering, Nanchang Hangkong University, Nanchang 330063, China \\ Correspondence should be addressed to Shuaixing Wang; wsxxpg@126.com
}

Received 25 January 2015; Accepted 9 June 2015

Academic Editor: Holger von Wenckstern

Copyright (c) 2015 Shuaixing Wang et al. This is an open access article distributed under the Creative Commons Attribution License, which permits unrestricted use, distribution, and reproduction in any medium, provided the original work is properly cited.

\begin{abstract}
The long-term corrosion rate of X80 steel in an acidic red soil was monitored in situ by using a precise electrical resistance (ER) test system. The corrosion characteristics of X80 steel were examined via SEM, EDS, and XRD. The results indicated that the corrosion rate determined from ER test was very similar to that obtained from the mass loss test. The ER test technique made it possible to predict the long-term corrosion rate of steel in soil in situ. The corrosion rate of X80 steel in acidic red soil was about $0.0902 \mathrm{~mm} / \mathrm{a}$ at 38 weeks, but the corrosion rate was dropped to $0.0226 \mathrm{~mm} / \mathrm{a}$ after 5 years. The final corrosion product layer was composed mainly of $\mathrm{FeOOH}, \gamma-\mathrm{Fe}_{2} \mathrm{O}_{3}$, and $\mathrm{FeCO}_{3}$.
\end{abstract}

\section{Introduction}

Pipelines are the preferred method for transporting large volumes of crude oil and natural gas over long distances. However, the susceptibility of pipeline steel to corrosion has a negative impact on the operation of the pipelines. In fact, the pipeline steel undergoes stress corrosion cracking (SCC) [14], pitting [5], or crevice corrosion [6] in various soils. Red clay soil constitutes one of the major soil types in Eastern and Southeastern China. This soil is acidic, in general, owing to the natural acidification including intensive weathering and leaching process under humid climate conditions [7]. It has been found that acidic red soils are extremely aggressive towards carbon steel [8], and the corrosion of pipeline steel in this kind of soil is more severe than that in neutral/alkaline soils [3,9-11]. Therefore, monitoring the corrosion rate of X80 steel in acidic red soil environments is crucial to addressing both cost and safety concerns.

In general, metal corrosion in soil can be measured simply and efficiently through long-term exposure in a soil test station; however, this method requires a long experiment period and the data is only obtained at the end of the corrosion process [12]. Recently, with the development of electrochemical measurement techniques, linear polarization, electrochemical impedance spectroscopy $[3,6,10]$, and electrochemical noise [13] and scanning Kelvin probe [14] measurements have become conventional methods for studying the soil corrosion. These methods provide relative information about metal corrosion in the soil. However, they are inadequate for describing the actual corrosion that occurs based on the physical and chemical characteristics of the soil. Therefore, it is essential to develop various real-time and in situ corrosion monitoring techniques for studying metal corrosion in soil. In recent, some methods or models for in situ monitoring soil corrosion have been proposed [15, 16].

The electrical resistance of a metal depends mainly on its geometry and intrinsic resistivity. Therefore, the corrosioninduced change in geometry of a metal can be used to determine the metal loss and corrosion rate. The electric resistance (ER) sensor has been widely used in many industries to determine the corrosion rate owing to the ease of measurement and interpretation [17-19]. However, the low sensitivity of 
these sensors has stymied their use for underground steel structures. Recently, some precision ER sensors have been invented and used to measure the corrosion kinetics of steel in the soil. For example, the ER sensor invented by Li $[20,21]$ can detect changes of $0.01 \mathrm{~mm} / \mathrm{y}$ or less in the corrosion rate. However, the sensitivities of most ER sensors are determined by measuring the short-term corrosion data. The use of the precision ER measurement technique for monitoring the long-term corrosion rate of pipeline steel in acidic soil environments remains unexplored.

As such, in this work, a precise ER test system was developed, and the relationship between the resistance variation and the corrosion rate of X80 steel was determined. The system was also used to monitor the corrosion rate of X80 steel during $5 \mathrm{y}$ of burial in acidic red soil. In addition, scanning electron microscopy (SEM) was used to examine the morphology, while energy dispersive X-ray spectroscopy (EDS) and X-ray diffraction (XRD) were used to determine the composition of the corroded steel.

\section{Experimental}

2.1. Material and Test Site. API-X80 pipeline steel was used for all the tests in this work. This steel had a chemical composition (wt\%) of C 0.055, Si 0.220, Mn 1.620, S 0.002, P $0.013, \mathrm{~V} 0.030$, Ti 0.009, Nb 0.070, and Fe balance. Specimens with dimensions of $100 \times \varphi 10 \mathrm{~mm}$ were tested. Prior to the tests, the specimens were ground with 240 and 800 grit emery papers, cleaned with deionized water and acetone, and dried in a stream of cool air. The ends of each specimen were machined screw threads of $8-10 \mathrm{~mm}$.

Nanchang $\left(28^{\circ} 41^{\prime} \mathrm{N}, 115^{\circ} 53^{\prime} \mathrm{E}\right)$ was the represented area of acidic red clay soil in Southeast China, according to the USDA soil taxonomy. This region had a typical subtropical monsoon climate, with a mean annual temperature, annual precipitation, and $\mathrm{pH}$ value of $17.7^{\circ} \mathrm{C}, 1600-1700 \mathrm{~mm}$, and 3.90-4.35, respectively. The specimens were buried at a depth of $1 \mathrm{~m}$ in the region. In addition, analysis results revealed that the soil in the region where the specimens were buried had a chemical composition (wt\%) of $\mathrm{Cl}^{-} 0.0066, \mathrm{SO}_{4}{ }^{2-} 0.0058$, and $\mathrm{HCO}_{3}{ }^{-} 0.0010$, a $\mathrm{pH}$ value of $\sim 4.7$, and a water content of $26 \% \pm 2 \%$. Specimens were buried for a total of $5 \mathrm{y}$ (from June 2009 to May 2014).

2.2. Test Principle. Resistance is the basic attribute of metal material. The resistance of metal is calculated from (1), where $R, \rho, l$, and $S$ are the resistance, resistivity, length, and sectional area of the specimen, respectively. Generally, the resistivity of a given metal is a constant, and therefore the resistance varies only with the geometry of the specimen. Furthermore, corrosion results in changes in the size of the specimen, and hence the ER changes. So, the corrosion depth can be calculated from the variation of ER.

Figure 1 shows the schematic of the dimensional variation of the clubbed X80 steel. If $\rho$ and $l$ are constant, then the resistance of the steel before $\left(R_{0}\right)$ and after $\left(R_{1}\right)$ corrosion is related through (2). Thus, the corrosion depth and corrosion rate can be calculated from (3) and (4). Here, $h$ is corrosion

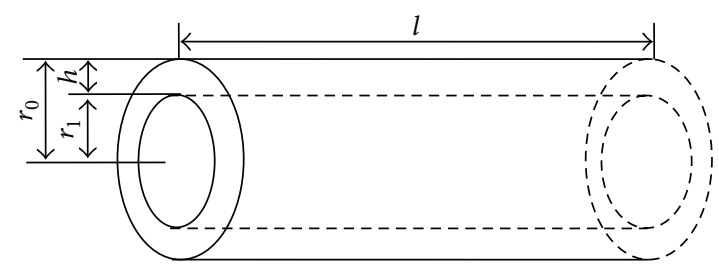

FIGURE 1: Schematic diagram of the dimension variation for clubbed X80 steel.

depth $(\mu \mathrm{m}), r_{0}$ and $R_{0}$ are the initial radius $(\mathrm{mm})$ and resistance $(\mu \Omega)$ of the specimen, $R_{1}$ is resistance $(\mu \Omega)$ of the corroded specimen, and $v$ and $t$ are corrosion rate $(\mathrm{mm} / \mathrm{a})$ and time $(\mathrm{y})$, respectively:

$$
\begin{aligned}
R & =\frac{\rho l}{S}, \\
\frac{R_{0}}{R_{1}} & =\left(\frac{r_{1}}{r_{0}}\right)^{2}=\left(1-\frac{h}{r_{0}}\right)^{2}, \\
h & =r_{0}\left(1-\sqrt{\frac{R_{0}}{R_{1}}}\right), \\
v & =\frac{h}{t} .
\end{aligned}
$$

Besides, the mass loss test was used in this work to evaluate the accuracy of the ER test. In the mass loss test, the corrosion rate was calculated from (5) [22], where $v, \Delta W, S$, $\rho$, and $t$ are the corrosion rate $(\mathrm{mm} / \mathrm{a})$, weight loss $(\mathrm{g})$, surface area $\left(\mathrm{cm}^{2}\right)$ of the specimen, density of the steel $\left(\mathrm{g} / \mathrm{cm}^{3}\right)$, and time (h), respectively:

$$
v=\frac{8.46 \times 10^{4} \Delta W}{S t \rho} .
$$

2.3. Test Setup. In this work, the electrical resistance of the specimens was measured by a precision resistance test system developed in our laboratory. Figure 2 shows the schematic of the electrical resistance test system and a photo of the fixture. As shown in Figure 2(b), the clubbed specimen was conducted with the wires through the fixture. The fixture consisted of copper nuts, brass bolts, and brass gaskets. Moreover, the fixtures were wrapped with PTFE film and epoxy resin in order to avoid the interference of soil on the conduction. This system allowed continuous in situ monitoring of the resistance of the steel specimen, with a precision of $0.1 \mu \Omega$. Besides, the system could monitor the variation of temperature and humidity and had the functions of data storage, data transmission, and temperature correction. The resistance displayed on the setup was the resistance corrected to $25^{\circ} \mathrm{C}$.

2.4. Surface Characterization. SEM (Quanta-200, FEI), EDS (INCA, Oxford), and XRD (D8-Advance, Bruker) were used to examine the morphology and determine the composition and phase structure of the corroded specimens, respectively. 


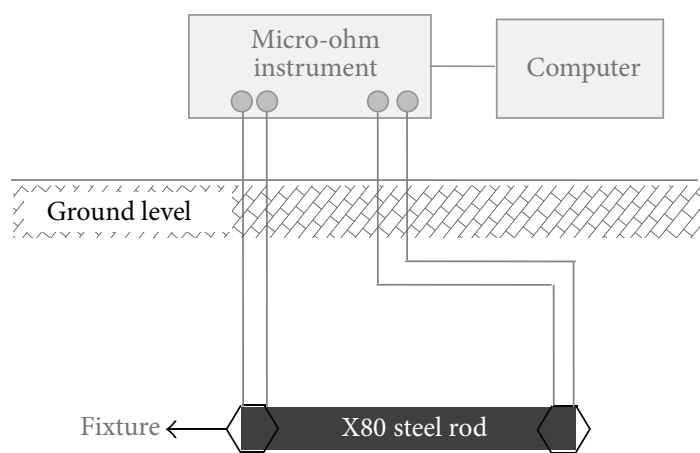

(a)

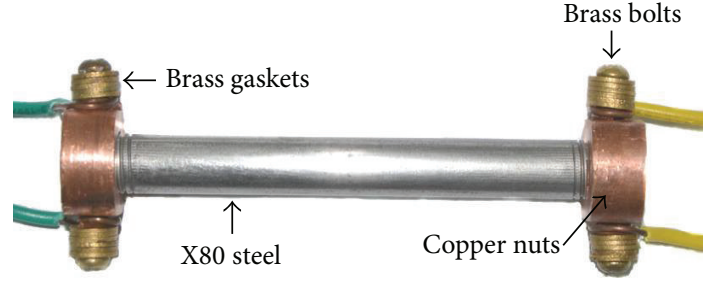

(b)

FIGURE 2: Schematic diagram of the electrical resistance test setup (a) and the photo of fixture (b) for clubbed X80 steel specimen in soil.

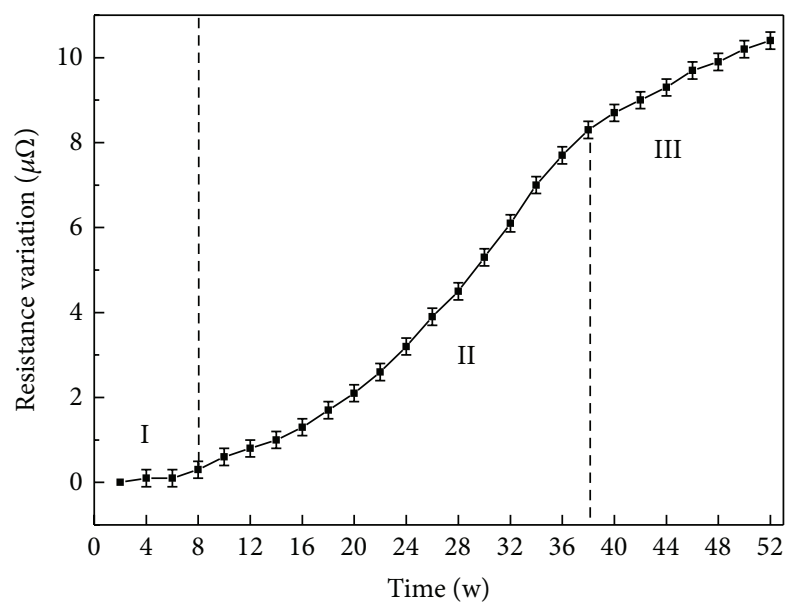

FIGURE 3: Variation curve of resistance addition for clubbed X80 steel in acidic red soil for 52 weeks.

\section{Results and Discussion}

3.1. Resistance Variation of X80 Steel. Figure 3 shows the variation in the resistance of the X80 steel buried in acidic red soil for 52 weeks. As it is shown, the resistance increases with increasing corrosion time, although not at a constant rate; that is, the plot can be divided into three stages, namely, I, II, and III. The resistance increased slowly in the initial stage (I) and then rapidly from 8 to 38 weeks (stage II). After 38 weeks (stage III), the rate of increase slowed but was still greater than that of the initial stage.

The variation in the resistance can be described by the parabolic law (6), where $\Delta R(t)$ is the added value of resistance at corrosion time $t$, and $A, B$, and $C$ are constants, and $|A|$ denotes the growth rate of the resistance. Table 1 shows the fitted values of $A, B$, and $C$ for different stages of the resistance variation curve:

$$
\Delta R(t)=A t^{2}+B t+C
$$

As shown in Table $1,\left|A_{\mathrm{II}}\right|>\left|A_{\mathrm{III}}\right|>\left|A_{\mathrm{I}}\right|$, which indicates that the increase rate of the resistance is largest, and the corrosion is most severe in the second stage. It is well known that soils with low amounts of moisture have poor
TABLE 1: Fitted values of $A, B$, and $C$ for the resistance variation curve.

\begin{tabular}{lccc}
\hline Corrosion stage & \multicolumn{3}{c}{$\Delta R(t)=A t^{2}+B t+C$} \\
& $A$ & $B$ & $C$ \\
\hline I & -0.0171 & 0.1929 & -0.1800 \\
II & 0.0326 & -0.1839 & 0.7016 \\
III & -0.0179 & 1.0964 & -6.1214 \\
\hline
\end{tabular}

conductivity. The transmission of active ions is difficult in soils with low moisture and hence the corresponding reactive resistance is high $[23,24]$. The backfilled soil has a water content of only $15 \%-18 \%$ as the evaporation when the soil is excavated. Therefore, the X80 steel corrodes only slightly and the resistance increases slowly when the specimens are initially buried. After a period (about 8 weeks), the properties of the soil near the specimens became similar to those of the soil surrounding the burial pit, owing to the physical, chemical, and atmospheric effects. In this stage, the amount of moisture and number of active ions increased significantly. The sites of low potential on the surface of the steel then corroded preferentially with the adsorption of active ions $\left(\mathrm{Cl}^{-}, \mathrm{HCO}_{3}{ }^{-}\right.$, etc.) $[25,26]$, and hence the corrosion rate increased substantially in stage II (i.e., from 8 to 38 weeks). Furthermore, the thickness and density of the corrosion product layer increased gradually with increasing corrosion time. This resulted in an increase in the protective effect of the corrosion product on the steel, which led to a significant reduction in the average corrosion rate.

3.2. Corrosion Rate of X80 Steel. Figure 4 shows the corrosion rate, as determined from the resistance variation of the X80 steel. As shown in Figure 4, the corrosion rate increases significantly up to 38 weeks and decreases thereafter, which is consistent with the variation in the resistance (Figure 3 ). The corrosion rate of X80 steel in acidic red soil decreases from $0.0902 \mathrm{~mm} / \mathrm{a}$ at 38 weeks to $0.0226 \mathrm{~mm} / \mathrm{a}$ after 5 years.

Besides, the corrosion rates calculated by the mass loss test are also shown in Figure 4. These rates exhibit a high degree of correspondence, except for a slight deviation in the initial stage of corrosion. The specimens were homogenized 


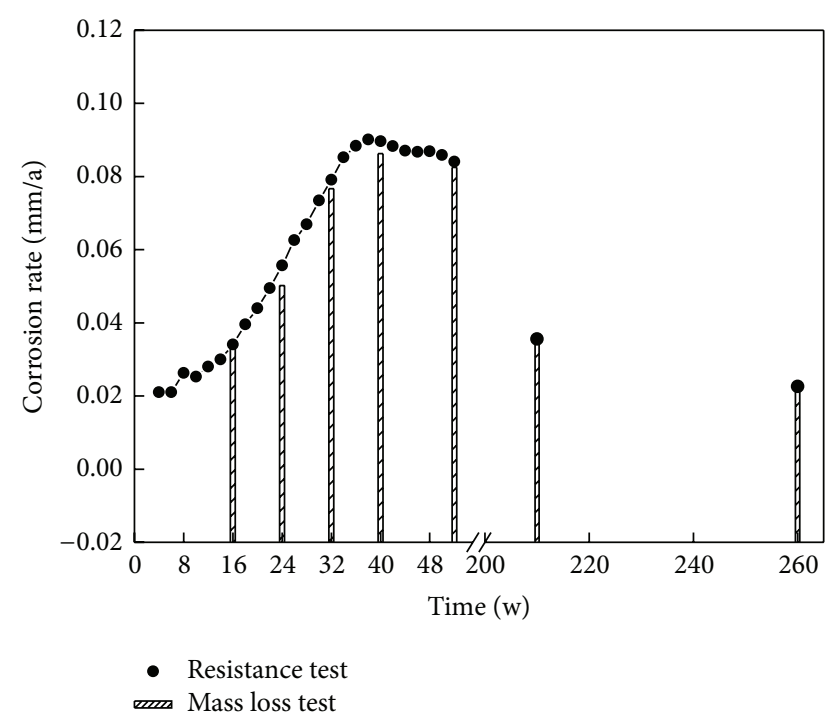

FIgURE 4: Corrosion rate of clubbed X80 steel specimens in acidic red soil for 5 years.

TABLE 2: Composition of corrosion product (Figure 5(a)) on X80 steel in red soil for 24 weeks.

\begin{tabular}{lccccc}
\hline \multirow{2}{*}{ Spectrum position } & \multicolumn{5}{c}{ Element (mass \%) } \\
& $\mathrm{Fe}$ & $\mathrm{O}$ & $\mathrm{C}$ & $\mathrm{Mn}$ & $\mathrm{Ca}$ \\
\hline Spec. 2 (outer layer) & 28.51 & 44.52 & 11.63 & - & 14.83 \\
Spec. 3 (inner layer) & 52.71 & 38.59 & 6.8 & 1.19 & 0.71 \\
\hline
\end{tabular}

in the principle of ER test technique, which was used to measure the general corrosion, and hence errors may have been generated when this technique was used to measure localized corrosion. General and localized corrosion should both occur when pipeline steel is buried in acidic soils [10, 11, 27]. Localized corrosion may be especially dominant in the initial stage, but severe general corrosion occurs with increasing corrosion time. Therefore, in the final stage of corrosion, the resistance and mass loss tests yield very similar corrosion rates, that is, a correspondence of $98.4 \%$ at $5 \mathrm{y}$. The present work shows that ER test technique was effective in continuously measuring the variation in the corrosion rate of X80 steel in acidic red soil.

3.3. Morphology and Chemical Composition. Figure 5(a) shows the sectional morphology and Table 2 lists the corresponding chemical composition of the corrosion product layer formed on X80 steel after 24 weeks. As shown in Figure 5(a), the corrosion product layer consists of two loose layers, namely, a thin inner layer and a thick outer layer. There were also many microholes in this product layer, and part of the outer product had peeled off. This indicated that the product layer offered only a low level of protection at 24 weeks, and the active ions in the red soil could continuously corrode the steel by passing through the microcracks.

In addition, XRD patterns of the corrosion product layers were shown in Figure 5(b). Table 2 and Figure 5(b) revealed that the outer layer had an $\mathrm{Fe} / \mathrm{O}$ atomic ratio of 0.183 and a phase composition of $\mathrm{FeO}(\mathrm{OH}), \mathrm{FeCO}_{3}$, and a small amount of $\gamma-\mathrm{Fe}_{2} \mathrm{O}_{3}$. This ratio and composition indicated that the outer corrosion product might be a mixture of $\mathrm{FeO}(\mathrm{OH})$ and $\mathrm{FeCO}_{3}$. However, the $\mathrm{Fe} / \mathrm{O}$ atomic ratio (0.390) and the higher intensity of the diffraction peak of $\mathrm{FeCO}_{3}$ suggest that the inner corrosion products are composed mainly of $\mathrm{FeCO}_{3}$. Furthermore, the $\mathrm{Ca}$ in the product layer originated primarily from the red clay soil. The migration path of this $\mathrm{Ca}$ was lengthened owing to the presence of the outer corrosion products and hence was present in only very low quantities in the inner product layer.

The sectional morphology, chemical composition, and phase composition of the corrosion product formed after 5 years were shown in Figure 6. This corrosion product layer had an average thickness of $\sim 120 \mu \mathrm{m}$, was more compact than that formed in 24 weeks, and consisted of only a single layer. However, it still contained many microcracks, especially at the sites near the substrate. The EDS spectrum (Figure 6(a)) showed that this layer had a uniform distribution of elements with $\mathrm{Fe}$ and $\mathrm{O}$ contents of $\sim 65 \%$ and $30 \%$, which varied only slightly from the outside to the inside. Moreover, the XRD spectrum (Figure 6(b)) showed that this corrosion product layer was composed of $\mathrm{FeOOH}, \gamma-\mathrm{Fe}_{2} \mathrm{O}_{3}, \mathrm{FeCO}_{3}$, and a small amount of $\mathrm{Fe}_{3} \mathrm{O}_{4}$.

3.4. Analysis of Corrosion Behavior. The anodic and cathodic reactions of X80 steel in red soil involve the dissolution of steel and the reduction of oxygen, respectively $[3,11,27]$. The main reactions are as follows:

$$
\begin{aligned}
& \mathrm{O}_{2}+4 \mathrm{H}^{+}+4 \mathrm{e} \longrightarrow 2 \mathrm{H}_{2} \mathrm{O} \\
& \mathrm{Fe} \longrightarrow \mathrm{Fe}^{2+}+2 \mathrm{e} \\
& \mathrm{Fe}^{2+}+2 \mathrm{H}_{2} \mathrm{O} \longrightarrow \mathrm{Fe}(\mathrm{OH})_{2}+2 \mathrm{H}^{+} \\
& \mathrm{Fe}+\mathrm{HCO}_{3}{ }^{-} \longrightarrow \mathrm{FeCO}_{3}+\mathrm{H}^{+}+2 \mathrm{e}
\end{aligned}
$$

The corrosion product film formed gradually on the steel surface with the accumulation of $\mathrm{Fe}(\mathrm{OH})_{2}$ and $\mathrm{FeCO}_{3}$. This film prevented the transport of active ions and thereby increased the reaction resistance. In addition, the XRD results indicated that the $\mathrm{Fe}(\mathrm{OH})_{2}$ was unstable and therefore generated other products through the following reactions:

$$
\begin{aligned}
4 \mathrm{Fe}(\mathrm{OH})_{2}+\mathrm{O}_{2}+2 \mathrm{H}_{2} \mathrm{O} & \longrightarrow 4 \mathrm{Fe}(\mathrm{OH})_{3} \\
\mathrm{Fe}(\mathrm{OH})_{3} & \longrightarrow \mathrm{FeO}(\mathrm{OH})+\mathrm{H}_{2} \mathrm{O} \\
2 \mathrm{FeO}(\mathrm{OH}) & \longrightarrow 2 \mathrm{Fe}_{2} \mathrm{O}_{3}+\mathrm{H}_{2} \mathrm{O} \\
6 \mathrm{Fe}(\mathrm{OH})_{2}+\mathrm{O}_{2} & \longrightarrow 2 \mathrm{Fe}_{3} \mathrm{O}_{4}+6 \mathrm{H}_{2} \mathrm{O}
\end{aligned}
$$

However, the following reactions occurred simultaneously in the presence of $\mathrm{H}^{+}$:

$$
\begin{array}{r}
\mathrm{FeCO}_{3}+\mathrm{H}^{+} \longrightarrow \mathrm{Fe}^{2+}+\mathrm{HCO}_{3}^{-} \\
\mathrm{FeO}(\mathrm{OH})+3 \mathrm{H}^{+}+\mathrm{e} \longrightarrow \mathrm{Fe}^{2+}+2 \mathrm{H}_{2} \mathrm{O}
\end{array}
$$

Owing to reactions (15) and (16), the corrosion product film became loose and many microcracks formed therein. 

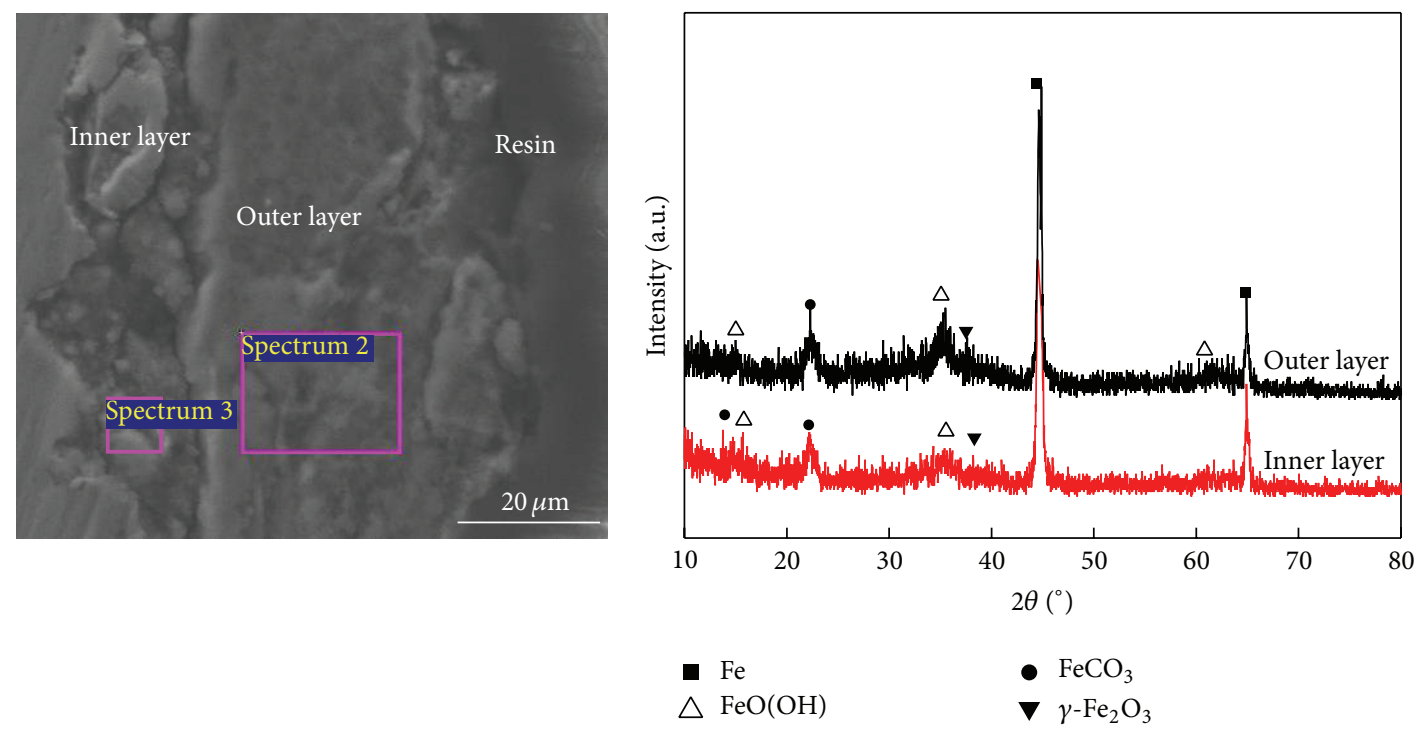

(a)

(b)

FIGURE 5: Sectional morphology (a) and XRD pattern (b) of corrosion product layers on X80 steel in red soil for 24 weeks.

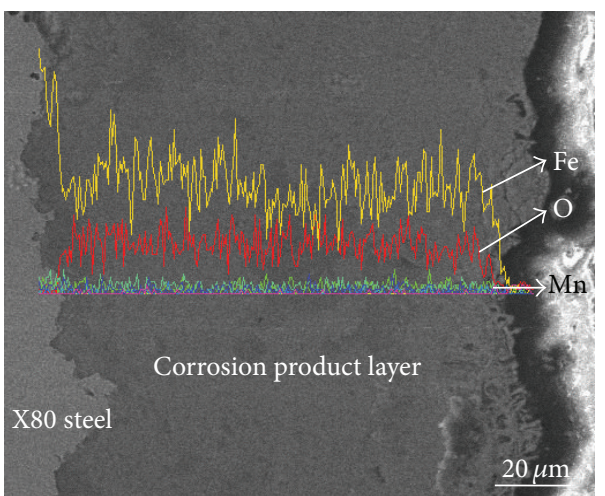

(a)

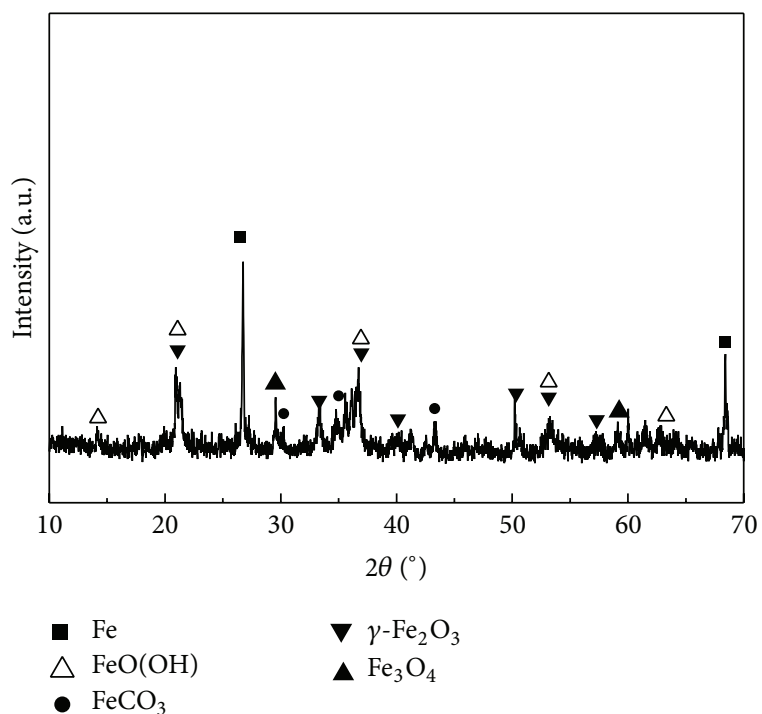

(b)

FIGURE 6: Sectional morphology and element composition (a) and XRD pattern (b) of corrosion product layers on X80 steel in red soil for 5 years.

In addition, the oxygen in the crevices of the corrosion product film was consumed gradually, but the sample was in full contact with the soil during the corrosion process [28]. The transfer rate of the oxygen in the crevices could not meet the requirement of the cathodic reaction, and hence an oxygen concentration cell formed; this resulted in the steel substrate being corroded preferentially under the crevices. As the corrosion progressed, the corrosion pores became active regions, and the accumulation of reactive ions in these regions resulted in a decrease in the reaction resistance.
Besides, the dissolution of defects in the product film increased with the adsorption of $\mathrm{Cl}^{-}$(from the red soil) on these regions. These combined effects intensified the corrosion of X80 steel and transformed into severe general corrosion in the final stage.

\section{Conclusion}

The corrosion rate of X80 steel in acidic red soil was determined based on the corresponding variation in resistance. 
In addition, electrical resistance and mass loss tests yielded very similar rates; a correspondence of up to $98.4 \%$ was obtained in the final stage of corrosion. Therefore, the electrical resistance test technique constitutes an effective means for continuously in situ monitoring of the corrosion kinetics of X80 steel in acidic red soil.

The corrosion rate of X80 steel in acidic red soil was about $0.0902 \mathrm{~mm} / \mathrm{a}$ at 38 weeks, but the corrosion rate was dropped to $0.0226 \mathrm{~mm} / \mathrm{a}$ after 5 years. Moreover, when X80 steel was exposed to acidic red soil for 24 weeks, a corrosion product layer consisting of two loose layers formed. The outer corrosion product was a mixture of $\mathrm{FeO}(\mathrm{OH})$ and $\mathrm{FeCO}_{3}$, whereas the inner product was composed mainly of $\mathrm{FeCO}_{3}$. However, after 5 years, the product layer consisted of only a single layer that was composed of $\mathrm{FeOOH}, \gamma-\mathrm{Fe}_{2} \mathrm{O}_{3}, \mathrm{FeCO}_{3}$, and a small amount of $\mathrm{Fe}_{3} \mathrm{O}_{4}$.

\section{Conflict of Interests}

The authors declare that there is no conflict of interests regarding the publication of this paper.

\section{Acknowledgment}

The authors would like to express their appreciation to National Natural Science Foundation of China (Grant no. 51161021) for providing the financial support to this work.

\section{References}

[1] P. Liang, X. Li, C. Du, and X. Chen, "Stress corrosion cracking of X80 pipeline steel in simulated alkaline soil solution," Materials and Design, vol. 30, no. 5, pp. 1712-1717, 2009.

[2] B. W. Pan, X. Peng, W. Y. Chu, Y. J. Su, and L. J. Qiao, "Stress corrosion cracking of API X-60 pipeline in a soil containing water," Materials Science and Engineering A, vol. 434, no. 1-2, pp. 76-81, 2006.

[3] Z. Liu, X. Li, Y. Zhang, C. Du, and G. Zhai, "Relationship between electrochemical characteristics and SCC of X70 pipeline steel in an acidic soil simulated solution," Acta Metallurgica Sinica, vol. 22, no. 1, pp. 58-64, 2009.

[4] A. Eslami, B. Fang, R. Kania et al., "Stress corrosion cracking initiation under the disbonded coating of pipeline steel in nearneutral pH environment," Corrosion Science, vol. 52, no. 11, pp. 3750-3756, 2010.

[5] Z. Y. Liu, X. G. Li, and Y. F. Cheng, "Understand the occurrence of pitting corrosion of pipeline carbon steel under cathodic polarization," Electrochimica Acta, vol. 60, pp. 259-263, 2012.

[6] M. C. Yan, J. Q. Wang, E. H. Han, and W. Ke, "Electrochemical measurements using combination microelectrode in crevice simulating disbonded of pipeline coatings under cathodic protection," Corrosion Engineering, Science and Technology, vol. 42, no. 1, pp. 42-49, 2007.

[7] R. Xu, A. Zhao, Q. Li, X. Kong, and G. Ji, "Acidity regime of the Red Soils in a subtropical region of southern China under field conditions," Geoderma, vol. 115, no. 1-2, pp. 75-84, 2003.

[8] C. N. Cao, Material Corrosion in Natural Environment of China, Chemical Industry Press, Beijing, China, 2005.
[9] M. Yan, C. Sun, J. Xu, and W. Ke, "Anoxic corrosion behavior of pipeline steel in acidic soils," Industrial \& Engineering Chemistry Research, vol. 53, no. 45, pp. 17615-17624, 2014.

[10] Z. Y. Liu, C. W. Du, X. Zhang, F. H. Wang, and X. G. Li, "Effect of $\mathrm{pH}$ value on stress corrosion cracking of X70 pipeline steel in acidic soil environment," Acta Metallurgica Sinica (English Letter), vol. 26, no. 4, pp. 489-496, 2013.

[11] X. Chen, C.-W. Du, X.-G. Li, C. He, P. Liang, and L. Lu, "Effects of solution environments under disbonded coatings on the corrosion behaviors of X70 pipeline steel in acidic soils," International Journal of Minerals, Metallurgy and Materials, vol. 16, no. 5, pp. 525-533, 2009.

[12] J. H. Fitzgeral, "Evaluating soil sorrosivity-then and now," Materials Performance, vol. 32, no. 10, pp. 17-19, 1993.

[13] J. Y. Huang, Y. B. Qiu, and X. P. Guo, "Analysis of electrochemical noise of X70 steel in Ku'erle soil by cluster analysis," Materials and Corrosion, vol. 60, no. 7, pp. 527-535, 2009.

[14] A. Q. Fu and Y. F. Cheng, "Characterization of corrosion of X65 pipeline steel under disbonded coating by scanning Kelvin probe," Corrosion Science, vol. 51, no. 4, pp. 914-920, 2009.

[15] N. N. Aung and Y.-J. Tan, "A new method of studying buried steel corrosion and its inhibition using the wire beam electrode," Corrosion Science, vol. 46, no. 12, pp. 3057-3067, 2004.

[16] X. H. Nie, X. G. Li, C. W. Du, and Y. F. Cheng, “Temperature dependence of the electrochemical corrosion characteristics of carbon steel in a salty soil," Journal of Applied Electrochemistry, vol. 39, no. 2, pp. 277-282, 2009.

[17] M. McKenzie and P. R. Vassie, "Use of weight loss coupons and electrical resistance probes in atmospheric corrosion tests," Corrosion Engineering, Science and Technology, vol. 20, no. 3, pp. 117-124, 1985.

[18] R. A. Royer and R. F. Unz, "Use of electrical resistance probes for studying microbiologically influenced corrosion," Corrosion, vol. 58, no. 10, pp. 863-870, 2002.

[19] A. Legat, "Monitoring of steel corrosion in concrete by electrode arrays and electrical resistance probes," Electrochimica Acta, vol. 52, no. 27, pp. 7590-7598, 2007.

[20] S. Y. Li, S. Jung, K.-W. Park, S.-M. Lee, and Y.-G. Kim, "Kinetic study on corrosion of steel in soil environments using electrical resistance sensor technique," Materials Chemistry and Physics, vol. 103, no. 1, pp. 9-13, 2007.

[21] S. Li, Y.-G. Kim, S. Jung, H.-S. Song, and S.-M. Lee, "Application of steel thin film electrical resistance sensor for in situ corrosion monitoring," Sensors and Actuators B: Chemical, vol. 120, no. 2, pp. 368-377, 2007.

[22] R. W. Revie, Uhlig's Corrosion Handbook, John Wiley \& Sons, New York, NY, USA, 3rd edition, 2011.

[23] C. A. M. Ferreira, J. A. C. Ponciano, D. S. Vaitsman, and D. V. Pérez, "Evaluation of the corrosivity of the soil through its chemical composition," Science of the Total Environment, vol. 388, no. 1-3, pp. 250-255, 2007.

[24] F. Jing, F. Pei, Z. P. Zhu et al., "Influence of moisture on corrosion behavior od steel ground rods in mildly deseritified soil," AntiCorrosion Methods and Materials, vol. 60, no. 3, pp. 148-152, 2013.

[25] X. Mao, X. Liu, and R. W. Revie, "Pitting corrosion of pipeline steel in dilute bicarbonate solution with chloride ions," Corrosion, vol. 50, no. 9, pp. 651-657, 1994.

[26] K. Videm and A. M. Koren, "Corrosion, passivity, and pitting of carbon steel in aqueous solutions of $\mathrm{HCO}_{3}{ }^{-}, \mathrm{CO}_{2}$, and $\mathrm{Cl}^{-}$," Corrosion, vol. 49, no. 9, pp. 746-754, 1993. 
[27] M. C. Yan, C. Sun, J. Xu, and W. Ke, "Electrochemical behavior of API X80 Steel in acidic soils from southeast China," International Journal of Electrochemical Science, vol. 10, pp. 1762-1776, 2015.

[28] B. Zhao, C. Du, Z. Liu, X. Li, J. Yang, and Y. Li, "Corrosion behavior of X80 steel in Yingtan soil simulated solution under disbonded coating," Acta Metallurgica Sinica, vol. 48, no. 12, pp. 1530-1536, 2012. 

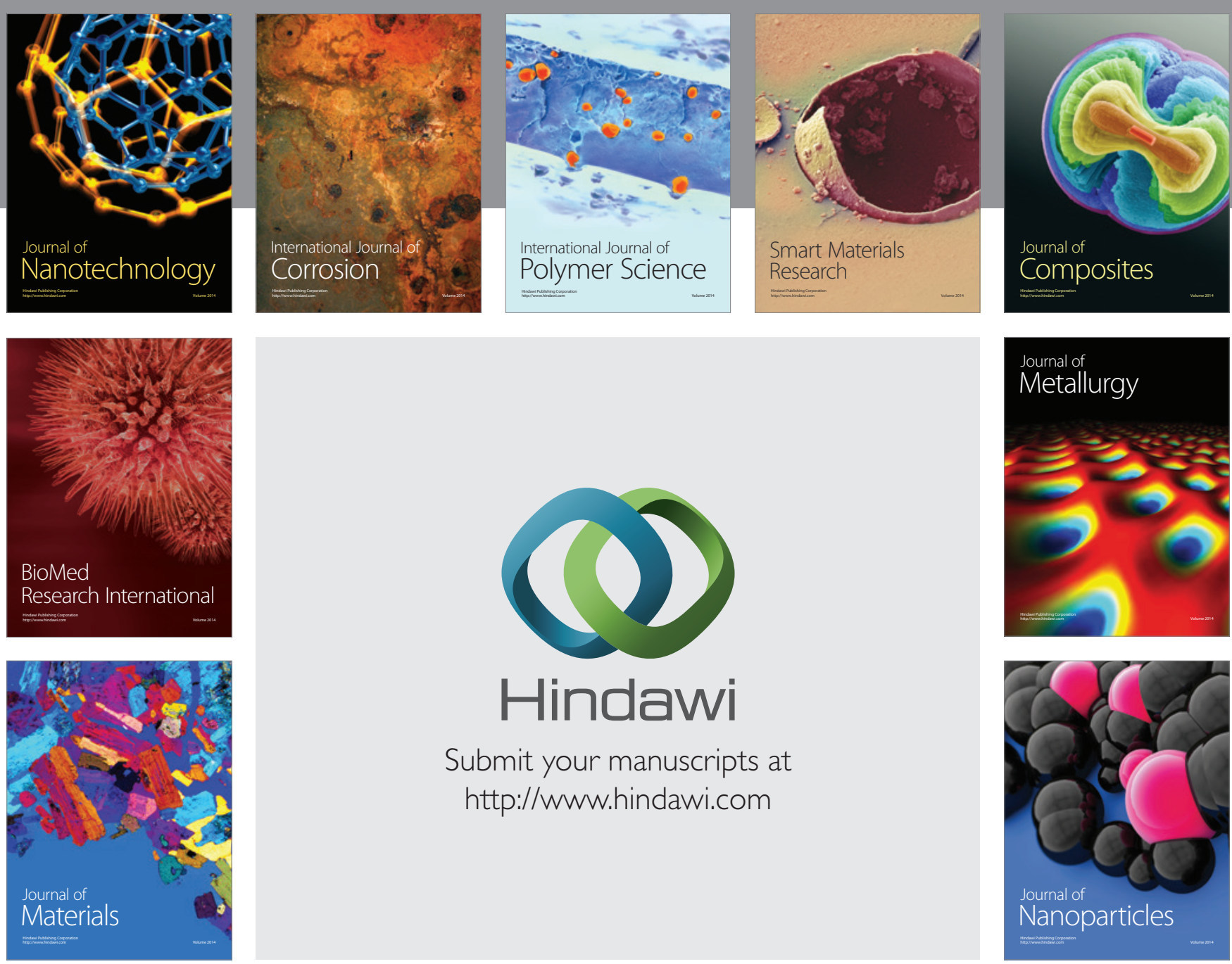

Submit your manuscripts at http://www.hindawi.com
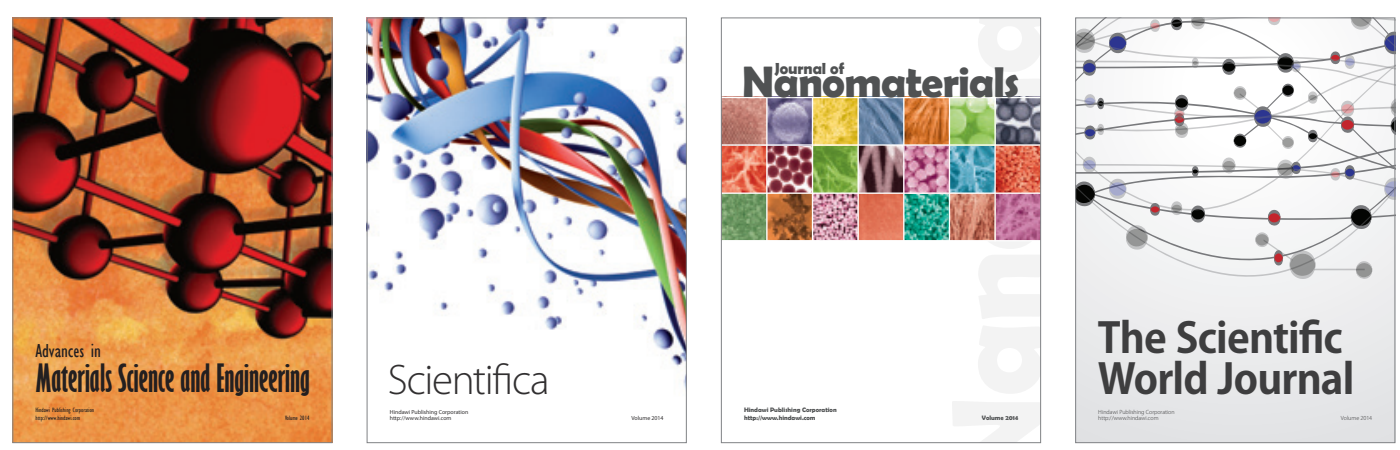

\section{The Scientific World Journal}
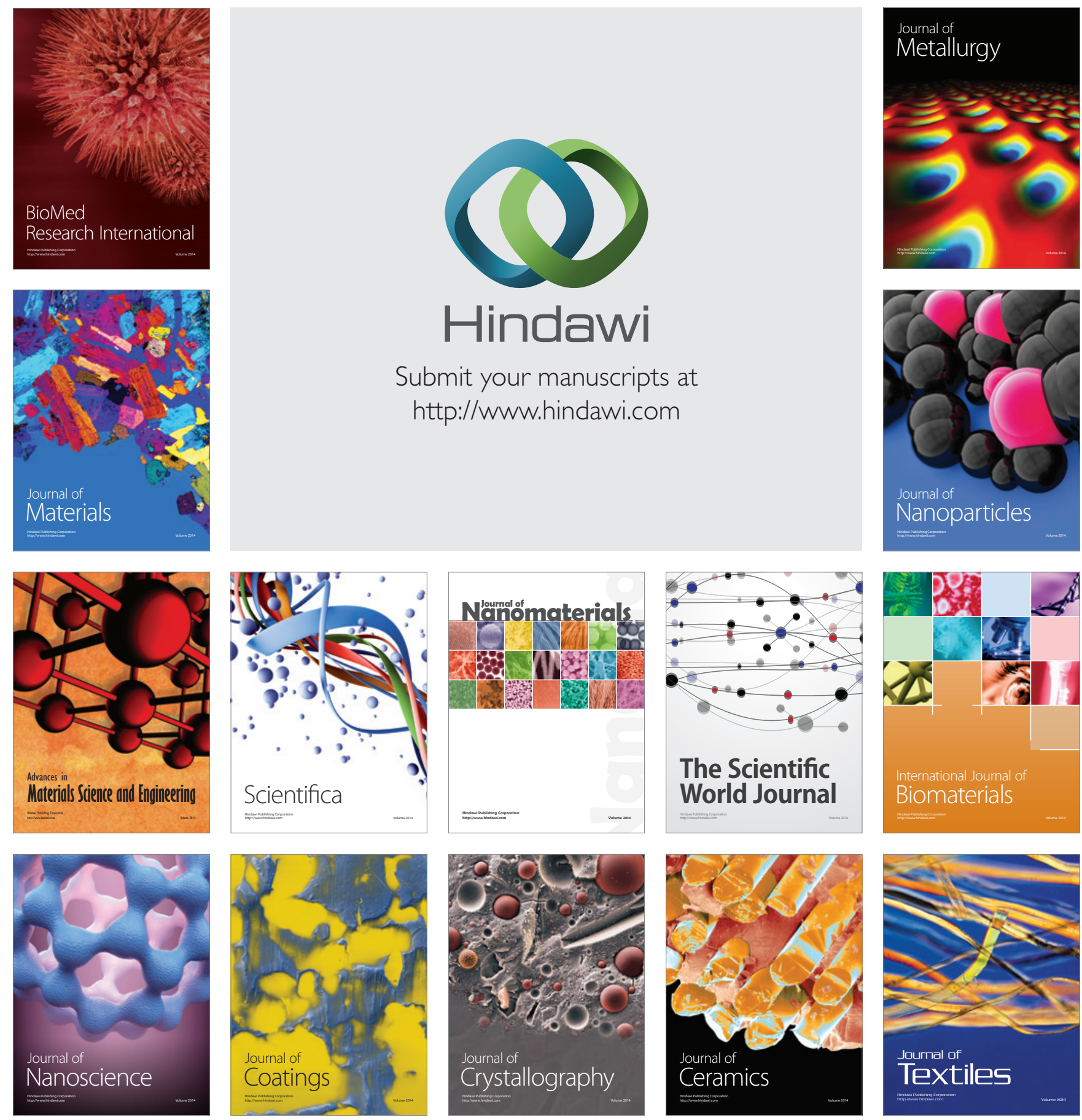